\title{
Pupils' view of problems: the evolution from kindergarten to the end of primary school
}

\begin{abstract}
Educators and several national standards highlight the role that problem solving should play in students' mathematics education: problem solving is recognized as one of the most significant activities of doing mathematics. From the research point of view, nowadays it is well established that cognitive and affective factors come into play in problem solving activities, but some affective issues remain unexplored. In particular, we want to study pupils' attitudes towards (mathematical) problems, analysing their evolution from kindergarten (where the word 'mathematics' is rarely explicitly mentioned) to primary school.

In a well-defined affective theoretical framework, where attitude is a three-dimensional construct including beliefs and emotions, we carried out a qualitative and narrative study involving 284 students of 7 different Italian schools: 121 from kindergarten and grade 1 and 163 from grade 3 to 5. Analyzing the qualitative data collected, we described primary students' attitudes towards problems and we compared these with those developed in kindergarten, where the word 'mathematics' is not explicitly mentioned.
\end{abstract}

\section{Introduction}

Affect and problem solving are two relevant, complex and related issues in educational research.

The field of affect in mathematics education has developed over the past three decades and is already consolidated in mathematics education, but some critical aspects are still present, mainly related to methodology (Hannula, Pantziara \& Di Martino 2018). In particular, there are great difficulties in involving young children (3-7 years) in research on affect, because much of the (qualitative) research on affect is based on self-reports.

The research on problem solving has a longer tradition, and has achieved several solid findings (Liljedahl, SantosTrigo, Malaspina \& Bruder 2016) also related to young students. Word problems have always been an important part of the primary school curriculum and the label 'mathematical problem' characterizes primary school jargon. On the other hand, even though primary school is where the attitude towards mathematical problems is born and often consolidates, few studies have been carried out on affective issues involved in young children's problem solving.

This paper stems from the idea that attitude can strongly influence students' approach to a problem and, more in general, to mathematics, and it is aimed at answering the following research questions: what are the pupils' attitudes towards problems in kindergarten and in primary school? What are the differences between these school levels?

In order to answer the research questions, firstly we will present and discuss re-analysed data originally collected to define students' attitudes towards mathematics (Di Martino \& Zan 2010; 2011). This new analysis will allow us to discuss the importance students give to problems in their mathematical experience and to obtain clues about students' attitudes towards a mathematical problem and their evolution over the primary school period.

Then, we will discuss the results of a new study specifically developed to compare students' views of problems and their emotions towards problems in kindergarten and in primary school.

Research on affect and research on problem solving also share a delicate issue regarding definition: in affective research, the constructs used are often undefined or their meaning in relation to other affective constructs is not made explicit; in problem solving research, there often is a discrepancy between the experts' definition of mathematical problem and the definition grounded in school practice.

For this reason, in the theoretical background of this paper we will clarify the meaning of the main constructs and describe the strong relationship between the development of the field of affect in mathematics education and research on problem solving (with particular reference to the primary school level).

\section{The field of affect in mathematics education}

During the Eighties there was a clear shift from a normative approach to an interpretative one in the field of mathematics education. Taking into account the complexity of the education process in mathematics, the main goal no longer lied in proving general rules based on a cause-effect schema, but it became that of understanding reasons for intentional actions. In this frame, several authors stressed how affect is a significant part of the mathematical education process and how, therefore, it cannot be ignored if we are interested in taking into account the richness and complexity of the educational process (Leron \& Hazzan 1997). This has led to the development of a specific field of research in mathematics education: the field of affect.

In what is considered to be the manifesto of this field, McLeod states: "if research on learning and instruction is to maximize its impact on students and teachers, affective issues need to occupy a more central position in the minds of researchers" (McLeod 1992, p. 575). McLeod's conceptualization of affect, located within a socio-constructivist perspective, identified three main affective constructs: beliefs, attitudes and emotions, which can be distinguished in terms of their stability and the degree to which cognition plays a role in each. Later, Goldin (2002) extended the categories of affect by introducing a new category, that of values.

Emotions are considered to be the most intensive and the least stable of the three constructs. According to Mandler (1984) emotional experience is the result of a combination of cognitive analyses and physiological responses; it arises when a schema is interrupted (a cognitive or perceptive discrepancy occurs between facts and expectations). Results 
from the field of cognitive neuroscience confirm the strong relationship between emotions and cognition: emotions play a crucial role in how memories are treated (it depends on whether memories are associated with pleasant emotions or unpleasant ones) and emotions affect the information processing style and the ability to make decisions (Bechara, Damasio \& Damasio 2003), which is particularly relevant for problem solving.

The literature on beliefs is probably the most extensive amongst the three main affective constructs in mathematics education. Despite this, the issue of definition remains unsolved: many researchers do not define the construct, assuming that readers know what beliefs are, or vice versa they have often formulated their own definition of belief which might even be in contradiction with others (Furinghetti \& Pekhonen 2002). Here, we take the large definition given by Philipp (2007, p. 259): "beliefs are psychologically held understandings, premises or propositions about the world that are thought to be true", they may be held with varying degrees of certainty and they are not necessarily consensual. Two categories of beliefs are particularly relevant for mathematics education: beliefs about self and beliefs about mathematics. Research on beliefs is interested in interpreting individuals' beliefs and in studying their (social, cultural and didactical) origins, the awareness and the degree of certainty of the individual with respect to the beliefs they hold, and the motives for changes in such beliefs.

The construct of attitude finds its origin in the context of social psychology. In the field of mathematics education, several studies on attitude focus on measurement issues without giving a clear characterization of the construct. This approach has shown great theoretical limits and promoted a movement towards the development of a shared definition of attitude (Di Martino \& Zan 2010). In particular, two main definitions have come forth: a simple definition that describes attitude as the positive or negative degree of affect associated to a certain subject; a multi-dimensional definition that recognizes three components of attitude: an emotional response, the beliefs about the subject, the behaviour towards the subject. These two characterizations both appear to be problematic: the absence of a connection with the cognitive aspects is criticized in the simple definition. On the other hand, the risk of circularity is evident for the multi-dimensional definition: attitude is a construct developed to interpret students' behaviour and students' behaviour is part of the definition of attitude (Di Martino \& Zan 2011).

Taking this perspective, we carried out a study aimed at constructing a grounded definition of attitude, that is a characterisation of the construct strictly linked to students' experience (Di Martino \& Zan 2010). With this aim, we proposed the autobiographical essay "Me and maths" to a large sample (1659) of Italian students: more than half of the sample was from primary school (precisely: 874 from primary school, grades 1-5; 381 from middle school, grades 6-8; 404 from high school, grades 9-13).

The analysis of the data collected led to the identification of the dimensions used by the students to describe their relationship with mathematics, and therefore to develop the following three-dimensional characterization of the construct (Figure 1).

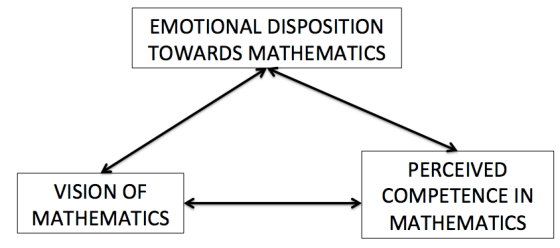

Figure 1: The Three-dimensional Model for Attitude (Di Martino \& Zan, 2010)

According to this model, the attitude towards mathematics is characterized by three dimensions, namely: the emotional disposition, the vision of mathematics and the perceived competence in mathematics. Referring to McLeod's approach, the construct attitude is made up of emotions associated to mathematics, beliefs about mathematics (vision of mathematics), beliefs about self, and their mutual relationship.

Over time, an individual's emotions, beliefs and attitudes towards mathematics appear to become more definite and stable (Hannula 2002). This result and the methodological difficulties in collecting self-reports with very young pupils are probably the main reasons for the lack of qualitative studies on kindergarten and primary school students' attitudes. In particular, in spite of the alleged increased variability of affective constructs, we know very little about if and how they can change at these school levels.

\section{Affect and mathematical problem solving}

Several mathematicians have identified problem solving as the heart of mathematics (Halmos 1980) and, on the other hand, mathematical (word) problems currently have an important role in the mathematics curriculum, mainly at primary school. This educational attention is also stimulated by official documents about primary school mathematics and its goals (NCTM 2000).

For many years, mathematical problem solving has been thought of as a type of cognitive activity par excellence: the famous work of Polya (1945) about problem solving developed a strong cognitive approach focused on heuristics. In those years, some allusions to emotions were made in the descriptions of creative processes followed by very famous mathematicians (Hadamard 1945; Poincaré 1952), but the allusion to emotions was confined to the excitement directly following the illumination (Liljedahl 2008, studied the "aha-experience" within the theoretical perspective of affect). 
During the Eighties, the increasing difficulties in the interpretation of some students' failures in problem solving led researchers to focus on the need to go beyond a purely cognitive approach in the analysis of students' performances in mathematical problem solving (McLeod 1992).

Schoenfeld (1985) illustrated through several examples how the students' mathematical world view (their beliefs about mathematics) affects the ways in which students behave when confronted with a mathematical problem. It influences their approach to the problem, what they perceive to be important in the problem, which techniques will be used or avoided, how long and how hard they will work on it, and so on. Along the same line, Cobb (1985) stressed how in problem solving activities the solver must give an initial meaning to the problem before applying a heuristic: beliefs play a crucial role in this meaning-making process.

On the other hand, the book "Affect and mathematical problem solving" (McLeod \& Adams 1989) highlighted the influence of the other two main affective constructs - emotions and attitudes - on students' concentration, persistence and activation of control processes during problem solving sessions. In particular, according to Mandler's theory (Mandler 1984), emotions are seen as the reactions to unexpected events and therefore they have a crucial role in problem solving contexts, where interruptions of schema should be recurrent.

During the following 25 years the attention towards affective factors in the educational research on problem solving grew and was consolidated: affective interpretations of problem solving phenomena became solid findings in the field of mathematics education (Goldin 2000; Hannula 2015). The overview of such research has led us to identify in it two different dimensions: a temporal one and one related to the definition issue.

The temporal dimension of the affective constructs considered refers to the distinction between state-type affective constructs describing dynamical processes and trait-type constructs describing rather stable dispositions (Hannula 2012). The studies focused on state-constructs describe how affective factors change and are related to cognitive factors in context: in particular, the development of motivational and emotional states throughout the problem solving process. Recent results regarding state-constructs in problem solving concern the idea of flow: an emotional state in which people are so involved in an activity that nothing else seems to matter (Liljedahl 2016). The studies focused on traitconstructs try to explain more general phenomena related to problem solving. A classical issue here is the already quoted gender gap (Caplan \& Caplan 2005), with evidence suggesting clear differences between boys and girls in terms of attitude towards mathematics (in particular, for what concerns self perception). A more recent issue is the study of students' affective reactions to new teaching environments (Bardelle \& Di Martino 2012).

The researchers' choice concerning this temporal aspect implies the choice of methods: quantitative methods can reveal stable categories (traits), but it seems to be unable to grasp quickly changing and very intense reactions (states). In particular, trait constructs are typically studied through self-reports while the state constructs are directly observed during problem solving sessions.

The definition dimension refers to the different possible characterizations of mathematical problem and problem solving. Some studies, focusing on school practice, analyse students' reactions to problems used in classrooms; others analyse students' behaviour in situations where mathematical problems that fit with an expert definition of problem are used.

The huge difference between the two kinds of conceptualization of a problem (expert and grounded in practice) appears to be particularly stressed at the primary school level. Experts describe problem solving as an activity in situations in which the solver has gotten stuck and the activation of productive thinking is needed (Perkins 2000), while the problems traditionally used in the classroom have a very different and stereotypical nature and can be correctly solved using rote learning (Sidenvall, Lithner \& Jäder 2015). This latter kind of highly stereotypical mathematical problems according to the literature, worldwide shared - on the one hand, highlights a strong, though perverse, view held by those who (teachers, textbook writers) write them; on the other hand, it assumes the form of a proper literary genre (Gerofsky 1996). This genre has a three-component structure: 1) a 'set up' component, establishing the characters and location of the putative story; 2) an 'information' component, which provides the information needed to solve the problem; 3) a question. Gerofsky explicitly speaks of 'alibi' in relation to the context of word problems used in primary school.

In this frame, several studies show that many students tend not to make any contextual considerations when solving word problems (Lesh \& Doerr 2003; Mellone, Verschaffel \& Van Dooren 2017; Mershet 1993): trying to understand the text of a problem is, in a certain sense, a waste of time. To by-pass the text, and therefore not consider the context, allows them to quickly reach the correct answer to word problems typically used in classroom (Zan 2011). As Sowder (1988) and Greer (1997) show clearly, a winning strategy for solving word problems at the primary school level is the following three-step mechanical process: select an arithmetic operation (this choice can be based on the identification of key words in the text), perform the computation, report the result.

This phenomenon is relevant because it gives origin to students' mechanical approach to the problems (Verschaffel, Greer \& De Corte 2000). It is a sort of paradox: students develop an unproblematic approach to mathematical problems! The awareness of the distance between the two conceptions of what is problem solving (expert and grounded in practice) appears to be crucial for the interpretation of research results and also for the possible implications for practice, both in terms of didactical action and of teacher development. Thus, it appears crucial that researchers interested in problem solving make explicit the object of their studies: are they mathematical problems according to the expert definition or according to the grounded definition? The focus of the present study refers to the grounded 
definition of (mathematical) problem and it tries to describe the main existing grounded definitions of problem in kindergarten and primary school.

\section{The occurrence of the word 'problem' in the primary students' autobiographical narratives}

In this section, we will provide a new analysis of the study (Di Martino \& Zan 2010; 2011) originally collected to define the construct of students' attitude towards mathematics. In particular, we will briefly discuss if and how primary students mention the word 'problem' in the description of their mathematical experience.

We proposed the autobiographical essay "Me and maths" to a large sample of Italian students, collecting 874 essays from primary school students (grades 1-5) and 785 from secondary school students (grades 6-13). Among them, 48\% of the essays refer to mathematical problems. Moreover, the occurrences of the term 'mathematical problem' in the secondary school students' narratives refer to elementary school memories in $72 \%$ of the cases.

Despite the fact that the Italian National Standards identify the end of grade 3 as an intermediate transition point towards the final educational goals of the primary school, a well-established tradition in mathematics teachers' practice tends to consider a different subdivision of the primary period: the first two years and the final three years. Indeed, the Italian Students Assessment - INVALSI - measure students' competence in mathematics at the end of grade 2 and at the end of grade 5 .

This de facto subdivision - different from the one in the National Standards - is also reflected within the data collected. Analysing the essays that speak of problems and their solutions, we noticed a very interesting evolution related to emotional disposition (see Table 1) starting exactly in grade 3.

\begin{tabular}{|c|c|c|c|c|}
\hline Grade & $\begin{array}{c}\text { Percentage of narratives } \\
\text { that include reference to a } \\
\text { 'mathematical problem' }\end{array}$ & \multicolumn{2}{|c|}{$\begin{array}{c}\text { Percentage of like/dislike/no emotional } \\
\text { disposition declared towards a problem } \\
\text { in the narratives that include reference } \\
\text { to a 'mathematical problem' }\end{array}$} \\
\hline $1-2$ & $28 \%(76$ of 267$)$ & $60 \%$ & $0 \%$ & $40 \%$ \\
\hline $3-5$ & $56 \%(343$ of 607$)$ & $38 \%$ & $19 \%$ & $43 \%$ \\
\hline Total $(1-5)$ & $48 \%(419$ of 874$)$ & $42 \%$ & $16 \%$ & $42 \%$ \\
\hline
\end{tabular}

In the first two years of primary school, about $60 \%$ of those who speak of problems explicitly mention their appreciation of problems: only 2 out of 267 narratives mention the fact that sometimes problems may not be liked. These two references are both connected to the third dimension of attitude (low self-confidence in mathematics) and, the initial symptoms of the fear of making mistakes emerge. Between $3^{\text {rd }}$ grade and $5^{\text {th }}$ grade the percentage of those who mention explicit appreciation for problems decreases to $38 \%$ and, more importantly, the percentage of those who express negative emotions towards mathematics increases by about the same amount (19\%). This phenomenon is explicitly correlated to the growing difficulty of problems and to the initial difficulties in solving them. These difficulties start appearing explicitly in the narratives of the $3^{\text {rd }}$ graders and strongly affect students' emotional disposition towards mathematics, and also their perceived competence in mathematics: Luca, a $4^{\text {th }}$ grade student, wrote: "The only thing I really do not like in mathematics is when it is required to reason and understand things that I do not know how to solve: for example, problems". The fear of making mistakes often becomes clear and intense, the pupils who find the strength to speak about their emotional difficulty describe strong feelings of uneasiness, that go far beyond simple pleasure/enjoyment: for example Serena, a grade 5 student, wrote: "When the teacher gives us problems, my hands shake, I may be able to do them, but I am terrified to make a mistake".

The change in the emotional disposition appears to be correlated with an increase of the perception of difficulty and a decrease of average perceived competence. It is relevant that both aspects are often exactly related to problem solving: in particular, if in the first years almost all children state that they are able to solve problems, in almost half of the $5^{\text {th }}$ graders' essays there is explicit reference to difficulties in approaching problems.

The references to mathematical problems in children's memories also concern the perception of utility in doing problem solving. From our narrative data, the majority of occurrences of the term 'useful' related to mathematical problems in primary students' narratives is referred to trading situations. On the other hand, in the children's narratives sometimes a naïve trust in the correspondence between arithmetical problems and life problems comes across, as shown by the following excerpt of a $3^{\text {rd }}$ grade student's essay: "About mathematics I think it is a fantastic subject because it can solve problems in everyday life: like dividing apples is a fraction, or the euro 1,50 is one and a half [...] Or maybe when the office manager is at work and has 86 collaborators but 17 are sick ad he wants to know how many collaborators there are he needs to do $86-17$ which is 69 and check it $69+17$ to see if it is right, in this case $69+17$ is $86 "$ ".

The narratives collected show a widespread view among children of what a mathematical problem is, what its characteristics are and what should be done to solve it. A mathematical problem is seen as a (more or less realistic) story in which there are numerical data to combine to obtain the answer to a question.

This grounded characterization of mathematical problem is perfectly in line with the following definition of word problem: "A text (typically containing quantitative information) that describes a situation assumed familiar to the reader and poses a quantitative question, an answer to which can be derived by mathematical operations performed on the data provided in the text, or otherwise inferred" (Greer, Verschaffel \& De Corte 2002, p. 271). 
The data show a considerable difference between grade 1-2 students and 3-5 students with respect to the perceived competence and emotional disposition towards problems, offering also a picture, though incomplete, of the third component of students' attitude toward problem (i.e. the vision of problems).

\section{The vision of problems at the preschool and primary school levels Rationale and method}

It appears evident that it is crucial to deepen our knowledge about what children identify when they refer to a problem in order to discuss their attitude towards problems. In particular, we were interested in analysing if and how students' vision of problems changes from kindergarten to the end of primary school.

In Italian language the word 'problema' ['problem' in English] has a twofold meaning: a general meaning (it indicates a question, situation, difficult case to solve and which generates concern) and a specific mathematical meaning. Since in kindergarten the word 'mathematics' is almost never explicitly mentioned, and it does not appear in the official standards for kindergarten, our study aimed at comparing the idea of problems held by children before they formally encounter the 'mathematical problem' (kindergarten through early $1^{\text {st }}$ grade) with the idea of problems held by older children (grades 3-5).

In order to do that, we collected data from 284 students (121 in kindergarten and grade 1, 163 in grade 3-5) of 7 different Italian schools in Tuscany. We have deliberately excluded grade 2 in our research because it is in a sort of limbo: for what we have discussed, grade 2 should have been associated to grade 1; on the other hand, in grade 2 children have already encountered mathematical problems.

The study was developed within a teacher development project on problem solving and argumentation at early school stages, involving 2 researchers in Mathematics Education and 49 teachers. The activities described in this paper were developed at the very beginning of the project. All teachers participated voluntarily to the teacher development project and also the collaboration for the study about students' attitude towards problem was voluntary.

The group of teachers involved in the collection of the data was very heterogeneous: participants differed in age, teaching experience and also mathematical teaching style. In this phase, the teachers were required to accomplish a crucial, but merely executive task: collect data through a specific format (differentiated according to the school level and school grade) and share the format with colleagues in their school. The part of teachers' active-participation - i.e. their discussion of the data with children, the discussion of the results in the project group meeting and the development of some related activities - is only partially documented in this paper.

From a methodological point of view, we had to face the great complexity of carrying out a study in affect with very young children, in addition to the fact that obviously we could not expect written text. In particular, we assumed that three phenomena could occur: the influence of what we can call adult desiderability, the tendency to replicate others' answers to open questions, the lack of labels to describe emotions.

These considerations guided the methodological choices. The collection of data was organized in three steps.

1- An individual section where teachers proposed the following open items: i) In your opinion, what is a problem? Give an example of a problem and of how you would solve it; ii) What don't you like about problems? Why? The choice of open questions was based on Cohen, Manion and Morrison's claim (2007, p. 249): "An open-ended question can catch the authenticity, richness, depth of response, honesty and candor which are the hallmarks of qualitative data". The second question was deliberately focused on disliking: in this way pupils can understand that the adult (the researcher/interviewer) considers natural that something can be disliked. We asked pupils in kindergarten and in $1^{\text {st }}$ grade (Group 1) to make a drawing of their example of a problem and then to explain it orally to the teachers (the interviews were audio-recorded); while older students (grade 3-5, Group 2) had to reply in writing. In primary school, the questions were proposed during school hours, but not during math class.

2- A group discussion where teachers illustrated the collected examples of problems and asked the children for their opinions about whether and how the problems were solvable. Then children chose their preferred examples and the teacher collected their opinions about the best way to solve the chosen problem. When the kind of chosen problem allowed it, teachers also encouraged children to implement their solutions in a dramatization of the problem. Pictures, videos and teachers' notes about this activity were a crucial part of the collected data.

3- A section of problem solving, in which teachers analyzed students' approaches to contextualized problem, exploiting what Di Martino and Baccaglini-Frank (2017) call the informational potential of standardized mathematical assessment. Problems were selected from those used in previous Italian National Standardized Assessments and, when deemed necessary, slightly adapted (for example using smaller numbers in kindergarten).

In the following, we focus mainly on the first two steps of the study.

Concerning the approach to the data, we adopted the analytical one suggested by Demazière and Dubar (1997): in this approach the data are analyzed in order to systematically construct a set of categories, properties, relationships, aimed at making sense starting from the respondents' answers. We will illustrate the categories through the choice of representative examples. 


\section{Results and discussion}

Group 1 (kindergarten and grade 1). As was predicted, in answering the first question of the individual section, the children in Group 1 did not refer to the mathematical problem, but to every day life problems. We collected a great amount of drawings and we tried to find categories of problems within these.

Except for some specific singularities, we classified the majority (almost three out of four) of problems produced by the children into three macro-categories: to be sick, to get hurt, to have some physical constraints or to die in the most extreme cases (Figure 2); something breaking or not working (Figure 3), to lose an object (Figure 4 and Figure 5).
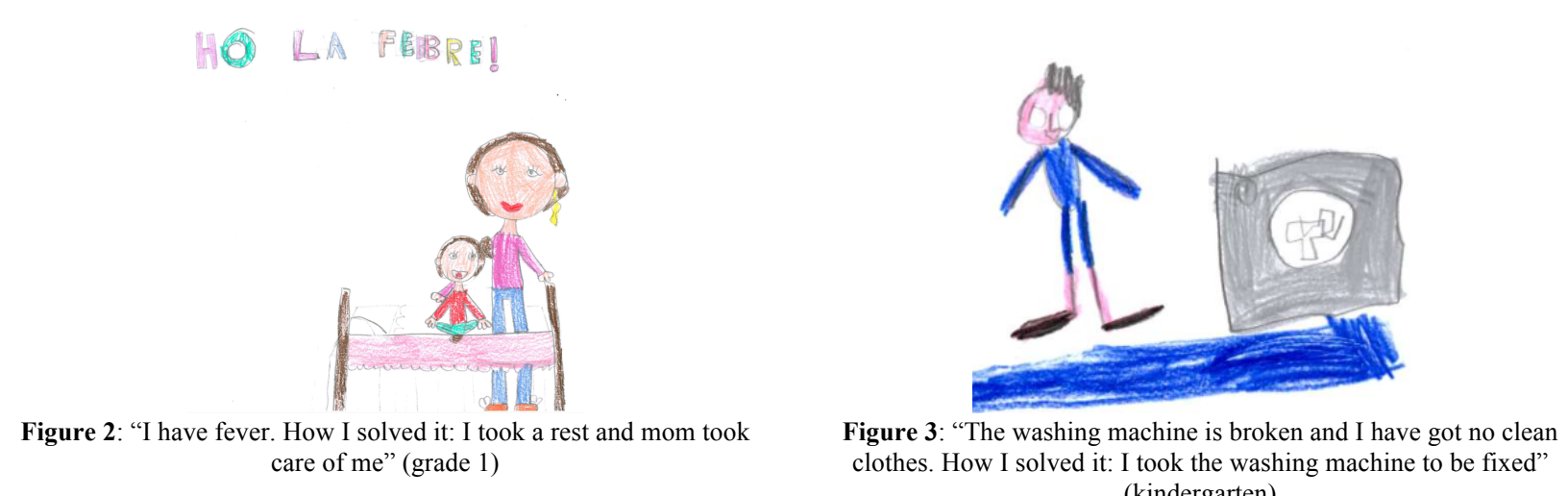

To lose an object is by far the most frequent category in the reported examples of problems: almost one out of two (57 of 121) students in Group 1 refer to this kind of problem. It would be interesting to further study this result from a sociological point of view.

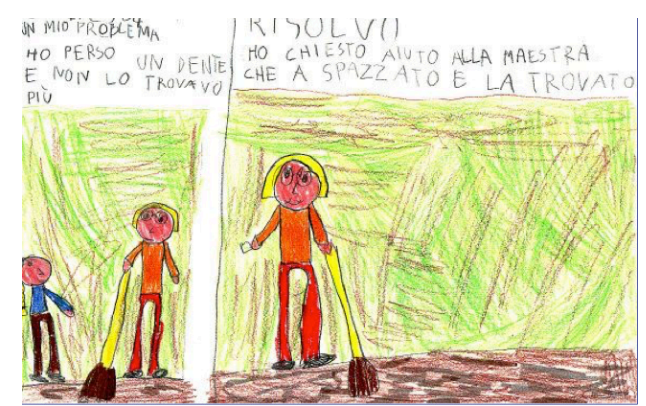

Figure 4: "I lost a tooth and I can't find it any more. How I solved it: I asked the teacher who swept [the room] for help and she found it" (grade 1)

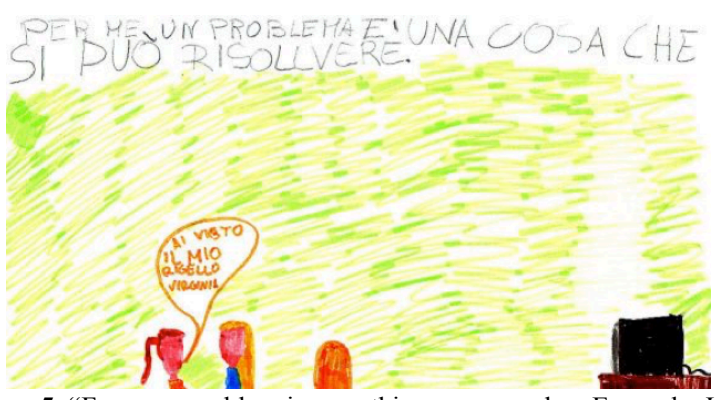

Figure 5: "For me a problem is something we can solve. Example: I lost my ruler. How I solve it: I can ask my friend Virginia: Did you see my ruler?" (grade 1)

The text in Fig. 5 shows an optimistic characterization of problems shared in Group 1: the only problem recognized as not being certainly solvable by all children is death. A thorough analysis of the data collected shows how the majority of the students characterize a problem as something that can be solved and they want to solve, but - at least initially they are not able to solve. Therefore, despite the shared optimistic view, students in Group 1 declared to be upset, sad and disheartened when a problem occurs because they are not able to do something they wish to do.

So, there seems to be a differentiation between a personal level (I am not able to do something: so there is a problem) and a social level (there exists someone who can solve the problem if we ask for his/her help).

As well as asking for help, three other ways of solving problems characterize the answers of students in Group 1: thinking/reasoning; trying in various ways; not giving up.

During the group discussion focusing on whether and how the problems were solvable, we observed, on the one hand the children's optimism about the possibility to solve almost all problems; on the other hand, their naturalness in analyzing in depth a solution, criticizing it and finding multiple solutions to a single problem.

For example, we report on the activity developed in a kindergarten with 25 children (age 5).

Cristina, the teacher, introduced the problem proposed by Anna: "A problem is when I cannot open the door because I cannot reach the door knob", asking children to propose and then dramatize their solutions. After an in-depth critical analysis of the pros and cons of the solutions proposed, children had to choose their preferred solution. Seven different solutions emerged: I jump (7 children, see Figure 6); I call dad/mom (5 children); I ring the bell (4 children); I take a ladder/a chair and I climb on it (3 children, see Figure 7); I go in the tavern and I get the keys (1 child); I wear my heels (1 child). 


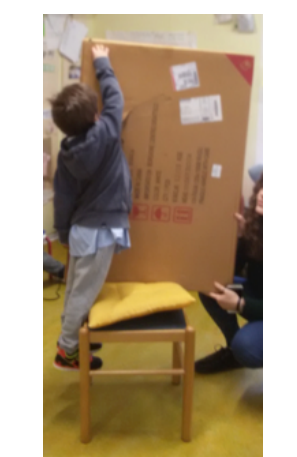

Figure 6: Luca: "I climb"

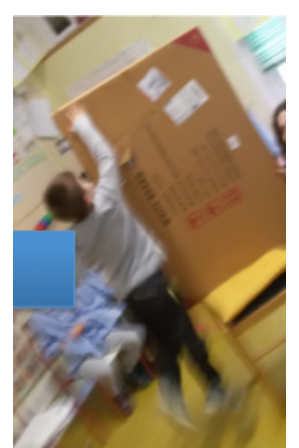

Figure 7: Andrea: "I would jump"

Group 2 (grade 3-5). The data collected offer a very different picture from the one emerging from Group 1. First of all, a problem is no longer characterized as something that students want to solve, but as something that must be solved (Grade 4: "a problem is a difficulty and we must resolve it"). The emergence of this normative/prescriptive component seems to be related to the fact that school problems are hetero-posed (i.e. posed by others). Zan (2011) developed meaningful reflections about the implications of this fact for children's sense making of the problematic situation described in the mathematical problem texts.

The second difference is the absolute predominance (156 answers out of 163) of mathematical problems in the collected examples of problems. The analysis of these examples allowed us to reconstruct a shared idea about what a mathematical problem is (and how to solve it) for these children.

A problem is a text, with a familiar context and a final question. The question has a unique numerical answer and it is necessary to combine all the numerical data present in the text with a single operation in order to get it. Moreover, except for extremely rare cases, combining all and only the data provided in the text (see Figure 8).

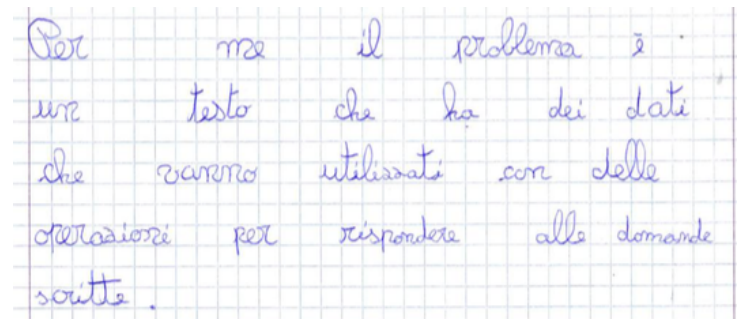

Figure 8: "For me, a problem is a text with some data. These data have to be used with some operations to answer to the written questions." (grade 4)

The emerging structure associated with a mathematical problem is rigid and stereotypical: the collected examples are pretty much shaped by an interchangeable frame, depending of the arithmetic operation involved. For example, considering problems that refer to the operation of subtraction, we found interchangeable texts all referring to the 'take away' meaning of subtraction (Grade 3: Paolo had 19 cookies, he ate 7. How many cookies are left?).

In particular, the context appears to be considered as completely irrelevant - an alibi using Gerofsky's (1996) words just like its trueness or realism. Almost all the examples collected refer to a real life context (apart from 12 examples of geometrical problems), but these problems are often immersed within rather unrealistic - or sometimes insignificant situations (Grade 5: A couple has 135 children, the three ninths of them are males. How many of them are female?).

The analysis of the group discussions about how to solve a problem also show significant differences compared to the opinions collected from Group 1. For the majority of the children in Group 2, a mathematical problem can always be solved, and it has only one solution, which should be reached in a single correct way. In particular, 26 children describe explicitly a shared standard procedure to solve a problem: highlighting data and finding keywords in the text, therefore finding the right arithmetical operation (tracing a drawing/diagram appears not very related to finding the solution, but it is something to do to please the teacher). In this view, numerical data and arithmetic operations are considered necessary in order to solve mathematical problems.

Analyzing the answers of Group 2 to the questions: What don't you like about problems? Why? it emerges that what students in grades 3-5 dislike is their inability to solve the problems and, therefore, the difficulty of a problem is considered to be a negative aspect. The answers collected show a worrisome evolution from grade 3 , where the evaluation is on being in a particular condition (state) of difficulty ("when I am not able to solve a problem I feel bad"), to grade 5, where frequently students make reference to an a priori evaluation (trait) of difficulty ("I am not able to solve problems, this is why when the teacher gives them to us I would like to go home"). This evolution seems to have an impact on the emotional disposition towards mathematical problems: in grades 4-5 the answers (and only for these grades) include statements expressing a definitive idea about the perceived competence in solving mathematical problems (Grade 4: "I feel so dumb"; Grade 5: "I will never be able to do this! When I have to solve a problem I hold my head in my hands and I despair").

The spread and the consequences of a mechanized approach to problems appear in simple problems where no operations are required. Within step 3 of the present study, we used the following problem from the 2009 Italian 
National Standardized Assessment for grade 5: "Maria, Renata and Fabio measure the length of their classroom through their step. Maria counts 26 steps, Renata counts 30 and Fabio 28. Who has the longest step?". Almost 50\% of the grade 5 students of the national sample chose the option 'Renata', and we obtained a similar percentage in our sample of students from grades 3 to 5 ( $43 \%$ of them answered 'Renata'). We proposed a similar problem at the kindergarten level (simply using smaller numbers in the text) and it was correctly solved by the children through an empirical approach: they used steps to calculate the length of their classroom noticing that the smaller children, with shorter steps, counted more steps.

\section{Conclusions}

The results obtained show a worrisome evolution between kindergarten and the end of the primary school of the students' attitude towards problems, in terms of the three components of attitude: vision, emotional disposition and perceived competence.

This is true throughout the primary school trajectory: the autobiographical essays of these students show that the percentage of those who express negative emotions towards mathematical problems increases from grade 1 to grade 5 and, at the same time, there is a decrease in average perceived competence in solving mathematical problems. But this is also true in the transition from kindergarten to the more structured (and directly linked to mathematics) primary school level. This phenomenon seems to highlight the negative effect of the exposition to the word problems in primary school.

Students in kindergarten and in the first year of primary school hold an idea of problems that appears to be very promising, not fixed to a stereotypical model. Also their idea about how a problem can be solved (their idea of problem solving) appears to be quite advanced: they do not describe prescriptive and reproductive actions. Moreover, in many cases, they accept and search for a multiplicity of solutions for the same problem, referring to actions such as collaborating with others, thinking/reasoning, trying in various ways, not giving up. We highlight how these ways of solving a problem contrast with the typical Italian setting for problem solving sessions (but also with the setting of international standardized assessments): students have little time to solve a problem (so it is difficult to think much, or to try in various ways) and cooperation is not encouraged, to say the least.

The common vision of problems developed at the end of primary school appears to be the exact opposite. This is another qualitative indicator of the deterioration of students' attitude towards problems: the development and consolidation of a stereotypical vision of the mathematical problem and of the (normative) way to solve it. This view appears to be extremely in contrast with the idea of mathematical competence and of the formative value of problem solving promoted by many educational official documents.

The fact that the vision of problems is much broader, open and productive in children who have not yet met the mathematical problem is an aspect to reflect upon: in a certain sense, it seems that educational experience - and, in particular, the exposition to mathematical problems in primary school - has a negative effect on students' vision of problems, but also on their self-perception and emotional disposition towards mathematical problems (i.e. on students' attitude towards mathematical problems).

These results have some educational implications for the initial school levels. The first one is related to the problem selection: the problems should allow and foster multiple approaches and solutions, they should refer to different situations in which mathematical operations (which play an important role in primary education) are involved, without enforcing the construction of a single meaning or way of using an operation (e.g., subtraction as discussed above). The second one is related to the need that teachers shift their attention from the product (numerical result) onto the process (students' strategies). This shift could also be a key to avoiding the development of students' worrisome fear to make mistakes in mathematical problems.

These implications for educational practice are clearly related to issues about teacher development. On the one hand, teachers need to have the knowledge to select problems appropriately and this is not always a practical reality at primary school level: Jakobsen and Ribeiro (2013) have shown, for example, elementary school teachers' difficulties in dealing with the different meanings of subtraction. On the other hand, teachers have to develop the ability to overcome fears: for example the fear of losing control when open activities are given or the fear of putting students in front of difficulties. This latter fear can lead to avoiding problems that are considered hard and to trivializing what is required, thus not allowing the development of meaningful activities. Recent research has shown how this avoidance of difficulties is devastating also because it blocks any form of education on addressing and overcoming difficulties in mathematics: in this manner, during their educational paths students who are good at math will not have developed the necessary cognitive and affective tools to react to difficulties in mathematics, and they will fall into deep crises at the first obstacle (Di Martino \& Gregorio 2018).

From a theoretical point of view, the originality of the study carried out lies within the following: the qualitative twostep methodology (with different degrees of specific focus on the object 'problem solving'), the richness of the data collected and analyzed, and having searched for a bottom-up characterization of problems (typically, studies on problem solving use the expert definition of problem or the characterization that researchers give of the mathematical problems used in class). On the other hand, the findings need further confirmation, possibly through the development of new methods to collect data at the kindergarten level on students' views of problems, on students' emotions during problem solving sessions and on students' self-confidence in solving problems. 
There are clear limitations of the study, but these open new alleys of research.

A first limitation of the study is that we are speaking of a cross-sectional study (and not of a longitudinal one): we are comparing children of different ages, without having access to the development of the attitude towards problems of each individual. In this case, as well, it would be very interesting to study the attitude of each single child throughout a longitudinal study.

Secondly, it is clear that the context and the culture play an important role in a study like the one described. Therefore, it would be particularly interesting to carry out similar studies in different contexts and cultures, and, later, compare results: how do children's attitudes evolve from kindergarten to the end of primary school? What elements of primary students' attitudes towards problems are common and which are different in different cultures? Moreover, what is the role of performance assessment on the development of students' attitudes towards mathematical problems? In Italy, there is no official assessment of children's performances in kindergarten.

\section{References}

Bardelle, C., \& Di Martino, P. (2012). E-learning in secondary-tertiary transition in mathematics: for what purpose?. ZDM-The International Journal on Mathematics Education, 44(6), 787-800.

Bechara, A., Damasio, H., \& Damasio, A. (2003). Role of the amygdala in decision-making. Annals of New York Academy of Science, 985, 356-369.

Caplan, J. B., \& Caplan, P. J. (2005). The perseverative search for sex differences in mathematics abilities. In A. Gallagher \& J. Kaufman (Eds.). Gender differences in mathematics: an integrative psychological approach (pp. 2547). New York: Cambridge University Press.

Cobb, P. (1985). Two children's anticipations, beliefs, and motivations. Educational Studies in Mathematics, 16(2), 111-126.

Cohen, L., Manion, L., \& Morrison, R. (2007). Research methods in education. London: Routledge Falmer.

Demazière, D., \& Dubar, C. (1997). Analyser les entretiens biographiques. Paris: Éditions Nathan.

Di Martino, P., \& Baccaglini-Frank, A. (2017). Beyond performance results: analyzing the informational and developmental potentials of standardized mathematics test. For the Learning of Mathematics, 37(3), 6-11.

Di Martino, P., \& Gregorio, F. (2018). The mathematical crisis in secondary-tertiary transition. International Journal of Science and Mathematics Education. https://doi.org/10.1007/s10763-018-9894-y

Di Martino, P., \& Zan, R. (2010). 'Me and maths': towards a definition of attitude grounded on students' narratives. Journal of Mathematics Teacher Education, 13(1), 27-48.

Di Martino, P., \& Zan, R. (2011). Attitude towards mathematics: a bridge between beliefs and emotions. ZDM-The International Journal on Mathematics Education, 43(4), 471-483.

Furinghetti, F., \& Pehkonen, E. (2002). Rethinking characterizations of beliefs. In G. C. Leder, E. Pehkonen, \& G. Törner (Eds.), Beliefs: a hidden variable in mathematics education? (pp. 39-57). Dordrecht: Kluwer.

Gerofsky, S. (1996). A linguistic and narrative view of word problems in mathematics education. For The Learning of Mathematics, 16(2), 36-45.

Goldin, G. (2000). Affective pathways and representation in mathematical problem solving. Mathematical Thinking and Learning, 2(3), 209-219.

Goldin, G. (2002). Affect, meta-affect, and mathematical belief structures. In G. Leder, E. Pehkonen, \& G. Törner (Eds.), Beliefs: a hidden variable in mathematics education? (pp. 59-72). Dordrecht: Kluwer.

Greer, B. (1997). Modelling reality in mathematics classrooms: the case of word problems. Learning and Instruction, 7 , 293-307.

Greer, B., Verschaffel, L., \& De Corte, E. (2002). “The answer is really 4.5”: beliefs about word problems. In G. Leder, E. Pehkonen \& G. Törner (Eds.), Beliefs: a hidden variable in mathematics education? (pp. 271- 292). Dordrecht: Kluwer.

Hadamard, J. (1945). The psychology of invention in the mathematical field. New York: Dover Publications.

Halmos, P. (1980). The heart of mathematics. American Mathematical Monthly, 87(7), 519-524. 
Hannula, M. (2002). Attitude towards mathematics: emotions, expectations and values. Educational Studies in Mathematics, $49(1), 25-46$.

Hannula, M. (2012). Exploring new dimensions of mathematics related affect: embodied and social theories. Research in Mathematics Education, 14(2), 137-161.

Hannula, M. (2015). Emotions in problem solving. In S. J. Cho (Ed.), Selected regular lectures from the $12^{\text {th }}$ international congress on mathematical education (pp. 269-288). New York: Springer.

Hannula, M., Pantziara, M., \& Di Martino, P. (2018). Affect and mathematical thinking: exploring developments, trends, and future directions. In T. Dreyfus, M. Artigue, D. Potari, S. Prediger \& K. Ruthven (Eds.), Developing research in mathematics education - twenty years of communication, cooperation and collaboration in Europe (pp. 128-141). London: Routledge Falmer.

Jakobsen, A., \& Ribeiro, M. (2013). Teachers' reflections on non-standard students work. In M. Ogunniyi, O. Amosun, K. Langenhoven, S. Kwofie \& S. Dinie (Eds.), Proceeding of the 21st annual meeting of the southern african association for research in mathematics (pp. 44-54). Cape Town: University of the Westen Cape.

Leron, U., \& Hazzan, O. (1997). The world according to Johnny: a coping perspective in mathematics education, Educational Studies in Mathematics, 32, 265-292.

Lesh, R., \& Doerr, H. (2003). Foundations of a models and modeling perspective on mathematics teaching, learning, and problem solving. In R. Lesh, \& H. M. Doerr (Eds.), Beyond constructivism: models and modeling perspectives on mathematics problem solving, learning, and teaching (pp. 3-33). Mahwah, NJ: Lawrence Erlbaum.

Liljedahl, P. (2008). The AHA! experience. Mathematical contexts, pedagogical implications. Saarbrücken: VDM Verlag.

Liljedahl, P. (2016). Flow: A Framework for Discussing Teaching. C. Csíkos, A. Rausch, \& J. Szitányi (eds.), Proceedings of the 40th conference of the IGPME (Vol. 3, pp. 203-210). Szeged, Hungary: PME

Liljedahl, P., Santos-Trigo, M., Malaspina, U., \& Bruder R. (2016). Problem solving in mathematics education. ICME13 Topical Surveys. New York: Springer.

Mandler, G. (1984). Mind and body: psychology of emotion and stress. New York: Norton.

McLeod, D. (1992). Research on affect in mathematics education: a reconceptualization. In D. Grouws (Ed.), Handbook of Research on Mathematics Learning and Teaching (pp. 575-596). New York: MacMillan.

McLeod, D., \& Adams, V. (Eds.). (1989). Affect and mathematical problem solving: a new perspective. New York: Springer.

Mellone, M., Verschaffel, L., \& Van Dooren, W. (2017). The effect of rewording and dyadic interaction on realistic reasoning in solving word problems. The Journal of Mathematical Behavior, 46, 1-12.

Mershet, K. (1993). How old is the shepherd? An essay about mathematics education. Phi Delta Kappan, 74, 548-554.

NCTM - National Council of Teachers of Mathematics (2000). Principles and standards for school mathematics. Reston, VA.

Perkins, D. (2000). Archimedes' bathtub: the art of breakthrough thinking. New York: W.W. Norton and Company.

Philipp, R. (2007). Mathematics teachers' beliefs and affect. In F. K. Lester, Jr. (Ed.) Second handbook of research on mathematics teaching and learning (pp. 257-315). Charlotte, NC: Information Age.

Poincaré, H. (1952). Science and method. New York: Dover Publications Inc.

Polya, G. (1945). How to solve it. Princeton: Princeton University Press.

Schoenfeld, A. (1985). Mathematical problem solving. Orlando: Academic Press.

Sidenvall, J., Lithner, J., \& Jäder, J. (2015). Students' reasoning in mathematics textbook task-solving. International Journal of Mathematical Education in Science and Technology, 46(4), 533- 552.

Sowder, L. (1988). Children's solutions of story problems. Journal of Mathematical Behavior, 7, $227-238$. 
Verschaffel, L., Greer, B., \& De Corte, E. (2000). Making sense of word problems. The Netherlands: Swets \& Zeitlinger.

Zan, R. (2011). The crucial role of narrative thought in understanding story problems. In K. Kislenko (ed.). Current state of research on mathematical beliefs XVI (pp. 287-305). Tallin: Tallin University. 